\title{
Intraocular Gene Transfer of Ciliary Neurotrophic Factor Prevents Death and Increases Responsiveness of Rod Photoreceptors in the retinal degeneration slow mouse
}

\author{
Michel Cayouette,, ${ }^{1}$ Darren Behn, ${ }^{2}$ Michael Sendtner, ${ }^{3}$ Pierre Lachapelle, ${ }^{2}$ and Claude Gravel ${ }^{1,4}$ \\ ${ }^{1}$ Laboratoire de Transfert de Gènes, Centre de Recherche Université Laval Robert-Giffard, Beauport, Québec, Canada, \\ G1J 2G3, 'Departments of Neurology/Neurosurgery and Ophthalmology, McGill University, Montreal Children's Hospital, \\ Montreal, Canada, H3H 1P3, ${ }^{3}$ Klinische Forschergruppe Neuroregeneration, Neurologische Universitäts-Klinik, Julius- \\ Maximilians-Universität, 97080, Würzburg, Germany, and 4Département de Psychiatrie, Faculté de Médecine, Université \\ Laval, Cité Universitaire, Québec, Canada, G1K 7P4
}

\begin{abstract}
Several mutations causing both photoreceptor degeneration and malfunction have been identified in humans and animals. Although intraocular injection of trophic factors has been shown to reduce photoreceptor death in a few conditions of rapid photoreceptor loss, it is unclear whether long-term beneficial changes in functional properties of affected photoreceptors can be obtained by treatment with these factors. The $r d s / r d s$ mouse is a spontaneous mutant bearing a null mutation in the rds/peripherin gene, which is linked to many forms of dominant retinal degenerations in humans. Here, we report that intraocular adenovirus-mediated gene transfer of ciliary neurotrophic factor (CNTF) in this mutant reduces photoreceptor
\end{abstract}

loss, causes a significant increase in the length of photoreceptor segments, and results in a redistribution and an increase in the retinal content of the photopigment rhodopsin. These effects are accompanied by a significant increase in the amplitude of the a- and b-waves of the scotopic electroretinogram. These results suggest that continuous administration of CNTF could potentially be useful for the treatment of some forms of retinal degeneration.

Key words: retina; ciliary neurotrophic factor; apoptosis; retinitis pigmentosa; gene transfer; photoreceptors; rhodopsin; electroretinogram
Retinitis pigmentosa (RP) is a group of inherited retinal diseases characterized by the progressive loss of photoreceptors, resulting in night blindness and visual field constriction. Over 20 loci have been linked to these diseases, and many RP-causing mutations have been uncovered in families affected by RP (Dryja and Li, 1995). These successes have allowed both the identification of spontaneous animal models of the disease and the production of genetically altered animal models bearing RP-causing genes (Bedell et al., 1997). These animal models provide the opportunity to test various therapeutic strategies for RP.

Recently, virus-mediated gene supplementation strategy has been tested in the autosomal-recessive retinal degeneration $(r d)$ mouse (Bennett et al., 1996; Jomary et al., 1997), and these experiments have provided proof of principle that $r d$ photoreceptors can be saved by reintroduction of wild-type copies of the $\beta$-phosphodiesterase gene. However, given the modest efficiency of gene transfer to photoreceptors and the fact that the usefulness of gene supplementation is probably limited for the most part to recessive and $\mathrm{X}$-linked forms of the disease, alternative strategies must be sought. One such strategy stems from the finding that all

Received June 16, 1998; revised Sept. 2, 1998; accepted Sept. 9, 1998.

This work was supported by grants from the Retinitis Pigmentosa Foundation of Canada (C.G.) and the Medical Research Council of Canada (C.G., P.L.), and by the Deutsche Forschungsgemeinschaft (M.S.). M.C. is the recipient of a studentship from Fonds pour la Formation des Chercheurs et d'Aide à la Recherche. We thank Richard Sidman for providing the $r d s$ founder mice, Robert Molday for the antiopsin and anti-rom-1 antibodies, and Ann Lorrain, Caroline Paquet, and Anita Kraiss for technical assistance.

Correspondence should be addressed to Dr. Claude Gravel, Laboratoire de Transfert de Gènes, Centre de Recherche Université Laval Robert-Giffard, 2601 de la Canardière, local F6500, Beauport, Québec, Canada, G1J 2 G3.

Copyright (C) 1998 Society for Neuroscience $0270-6474 / 98 / 189282-12 \$ 05.00 / 0$
RP-causing mutations studied so far in animal models lead to apoptotic death of photoreceptors (Chang et al., 1993; PorteraCailliau et al., 1994). In recent years, many neurotrophic factors have been identified that can prevent programmed cell death in selected neuronal populations in vitro and in vivo (Ip and Yancopoulos, 1996). Because intravitreal administration of some trophic factors and cytokines was found effective in reducing inherited or photoinduced photoreceptor loss in rats (Faktorovich et al., 1990; LaVail et al., 1992), neurotrophic factor therapy has been tested in mouse mutants bearing RP-causing mutations. In the $r d$ mouse, it was found that an intraocular increase in NGF (Lambiase and Aloe, 1996) or CNTF (Cayouette and Gravel, 1997; LaVail et al., 1998) can significantly slow down photoreceptor loss. However, it remains to be addressed if photoreceptors rescued by neurotrophic factor administration are functional.

We have investigated the effects of CNTF gene transfer in preventing photoreceptor death in the homozygous $r d s$ mouse, which exhibits a loss of photoreceptors caused by a null mutation in the rds/peripherin gene. This gene encodes a structural component of the membranal stacks that compose the outer segments (OS) of photoreceptors (Molday et al., 1987). Mutations in $r d s /$ peripherin have been found in families affected with various forms of dominant retinal degenerations, including RP (for review, see Dryja and Li, 1995). We show here that exposing $r d s$ retinas to increased levels of CNTF not only prevents photoreceptor loss, but also leads to morphological and biochemical changes associated with a net increase in scotopic electroretinogram (ERG) responses. These results suggest that the beneficial effects of CNTF on degenerating photoreceptors can go beyond the simple 
blockade of the apoptotic pathway and lead to an improvement of rod function in the homozygous $r d s$ mouse.

\section{MATERIALS AND METHODS}

Animals and intravitreal injection procedures. All animal work was performed in accordance with the guidelines of the American Society for Neuroscience. Homozygous Balb/C rds/rds breeders were obtained from R. Sidman (New England Regional Primate Research Center). All animals were $21 \mathrm{~d}$ old (P21) at the time of injection (the day of birth is P0). Mice were anesthetized by intraperitoneal injection of ketamine/ xylazine and held in a stereotaxic frame (Kopf). Intravitreal injections were performed under a stereomicroscope, using a glass capillary or a Hamilton syringe fitted with a 33 gauge blunt-ended needle. The capillary was inserted into the vitreous body through a small incision made in the superior hemisphere, going through the superior retina. One microliter of either the adenoviral vector Ad-CNTF $\left[2.9 \times 10^{7}\right.$ plaque-forming units (pfu)] (Cayouette and Gravel, 1997), or the adenoviral vector Ad-LacZ $\left(2 \times 10^{7} \mathrm{pfu}\right)$ (Vilquin et al., 1995) was injected over a period of $1 \mathrm{~min}$, and the needle was left in place for 2-3 min after injection. The Ad-CNTF vector is a defective Adenovirus serotype 5 virus in which a cntf gene, fused to the leader sequence of the nerve growth factor gene (Sendtner et al., 1992), and placed under control of the cytomegalovirus immediate/early promoter, replaces the E1 region of the viral genome. The Ad-LacZ vector is similar to Ad-CNTF, with the exception that an Escherichia coli lac $Z$ gene replaces the $n g f$-cntf fusion gene in the viral genome. In some cases, $500 \mathrm{ng}$ of purified rat recombinant CNTF (rrCNTF, PeproTeck), or 500 ng $\beta$-galactosidase (Life Technologies, Gaithersburg, MD), or vehicle only (0.01 M Tris, $\mathrm{pH} 7.6$, and $10 \%$ glycerol), also in a volume of $1 \mu \mathrm{l}$, were injected into the vitreous. All animals that had received an injection of Ad-CNTF or $\operatorname{rrCNTF}$ into one eye received a control injection of vehicle, $\beta$-galactosidase, or of AdLacZ into the contralateral eye, so that one eye could serve as an internal control in every injected animal. In some cases, as indicated in Results, the contralateral eye was left uninjected. Animals were kept under cyclic light (12 hr light/dark cycle) until killing.

Histology and immunohistochemistry. At 4, 14, or $52 \mathrm{~d}$ post-injection (p.i.), animals were sacrificed, and both eyecups from the same animal were fixed by immersion in $4 \%$ paraformaldehyde and frozen in the same embedding mold, so that sections from both retinas could be mounted on the same slide (Cayouette and Gravel, 1997). For immunohistochemistry, the sections were incubated overnight at $4^{\circ} \mathrm{C}$ with either anti-CNTF rabbit antiserum (Stöckli et al., 1991), anti-opsin antibody rho 1D4 (Molday and MacKenzie, 1983), or anti-rom-1 antibody (Moritz and Molday, 1996) diluted in PBS, 0.1\% Triton X-100, and 5\% donkey serum at ratios of 1:2000, 1:100, and 1:20, respectively. Bound antibodies (antiCNTF or anti-opsin) were detected by incubation for $2 \mathrm{hr}$ in either donkey anti-rabbit or donkey anti-mouse biotinylated antibodies, followed by a $1 \mathrm{hr}$ incubation in streptavidin-FITC (all from Jackson ImmunoResearch, West Grove, PA). A more sensitive ABC-alkaline phosphatase kit (Vector Laboratories, Burlingame, CA) was used to detect anti-rom-1, and in some cases anti-CNTF, immunoreactivity.

Morphometric and quantitative analyses. Outer nuclear layer (ONL) thickness (the distance from the innermost to the outermost extent of the layer excluding the photoreceptor segments) was measured using a calibrated graticule. For each eye, five measurements were taken at 50-75 $\mu \mathrm{m}$ intervals along the length of the ventral retina, starting $200 \mu \mathrm{m}$ from the ora serrata and progressing toward the central retina, on each of four hematoxylin-eosin-stained sections encompassing the optic nerve head, and spaced $60 \mu \mathrm{m}$ apart. Measurements were conducted on the ventral retina to avoid the artifact caused by the needle penetration site in the dorsal retina. The mean of the 20 measurements collected was used as the estimate of ONL thickness for each eye. All statistical comparisons were made using one-way ANOVA and Dunnett's multiple comparison tests. Photoreceptor segment (PS) length (the distance from the outermost limit of photoreceptor nuclei to the tip of the segments) was measured using a calibrated graticule, following the same sampling procedure used for measuring ONL thickness, and the data were analyzed using the same statistical tests.

Bioassays. At 4 or 14 d p.i., the animals were sacrificed and the eyes were enucleated and individually frozen in liquid nitrogen, pulverized, and the powder was resuspended in $150 \mu \mathrm{l}$ of ice-cold $0.005 \mathrm{M}$ phosphate buffer, $\mathrm{pH} 7.0$, containing $0.03 \mathrm{M} \mathrm{NaCl}$. These suspensions were then centrifuged at $25,000 \times g$ for $30 \mathrm{~min}$ at $4^{\circ} \mathrm{C}$, and the supernatant was collected. Protein concentration of each sample was determined, and aliquots were used in a survival assay using chick ciliary ganglion neurons (Hughes et al., 1988) to determine their content in CNTF-like activity. One trophic unit is the quantity of extract supporting halfmaximal survival of ciliary neurons. For the $\operatorname{rrCNTF}$ used in our experiments (obtained from Peprotech), one trophic unit corresponded to $9 \mathrm{pg}$ of CNTF.

Electroretinographic recording. All ERG recordings were performed by the same experimenter (D.B.), who was blind to the treatment applied to each eye. Before ERG recordings, the mice were dark-adapted for at least $12 \mathrm{hr}$ and then anesthetized with a mixture of ketamine $(150 \mathrm{mg} / \mathrm{kg})$ and xylazine $(7 \mathrm{mg} / \mathrm{kg})$. Under dim red light illumination, the pupils were dilated (1\% cyclopentolate hydrochloride), and an ERG electrode (blunt Grass E2 subdermal electrode) was placed on the corneal surface, which was kept moist with $1 \%$ methylcellulose. A reference electrode (Grass E5 disk electrode) was placed in the mouth, and a ground electrode (Grass E2 subdermal electrode) was inserted into the tail. During the entire recording procedure, the mouse was kept warm with the use of a heat exchange system of our design. Scotopic intensity response functions were generated with flashes of white light (Grass PS 22 Photostimulator), $20 \mu \mathrm{sec}$ in duration, spanning over a $4 \log$ unit range with a maximal intensity of $0.9 \mathrm{log} \mathrm{cd} / \mathrm{m}^{-2} / \mathrm{sec}$ in energy, and delivered in full-field illuminating conditions, according to a method previously reported (Lachapelle and Blain, 1990). Each response represented an average of two to five flashes depending on the intensity of the stimulus. To avoid the conditioning flash effect previously reported to affect dark-adapted ERGs, a minimum interstimulus interval of $10 \mathrm{sec}$ was maintained (Peachey et al., 1987; Lachapelle et al., 1990). To obtain photopic ERGs, a diffusing screen fitted with miniature halogen lamps was placed between the flash stimulator unit and the mouse to provide a background illumination of $30 \mathrm{~cd} / \mathrm{m}^{-2}$. A bright white flash stimulus $\left(0.9 \mathrm{log} \mathrm{cd} / \mathrm{m}^{-2}\right)$ sec in energy) was used to generate each photopic ERG, which represented an average of 20 responses. All responses were averaged and stored using the Acknowledge (Biopac MP100; Biopac Systems, CA) data acquisition system. For ERG waveform analysis, the a-wave was measured from the prestimulus baseline to the first negative peak of the ERG response, while the b-wave amplitude was measured from the a-wave peak to the most positive peak of the evoked response. Statistical significance was determined using ANOVA or paired $t$ tests. At the end of the ERG session, the mouse was euthanized, and the eyes were collected, fixed, and processed for histology, as well as for anti-CNTF and anti-rhodopsin immunofluorescence, as described above.

Protein extracts and Western blotting. Mice were euthanized and both eyes were collected, after which each retina was dissected in ice-cold PBS containing $10 \mathrm{~mm}$ EDTA and $2 \mu \mathrm{g} / \mathrm{ml}$ aprotinin and individually frozen in liquid nitrogen. Tissue extracts were prepared by adding $90 \mu \mathrm{l}$ of extraction buffer: Tris $0.25 \mathrm{M}$, pH 7.8; $1 \%$ Triton X-100; $10 \mathrm{~mm}$ EDTA; $2 \mu \mathrm{g} / \mathrm{ml}$ aprotinin (for rhodopsin analysis, extraction buffer contained no Triton) and kept on ice for $20 \mathrm{~min}$. Extracts were sonicated and then centrifuged at $4^{\circ} \mathrm{C}$ for $10 \mathrm{~min}$ at $8000 \times \mathrm{g}$. Supernatants were collected, and the protein concentrations were determined with the BCA protein assay (Pierce, Rockford, IL). Fifteen micrograms (for rom-1 analysis) or $3 \mu \mathrm{g}$ (for rhodopsin analysis) of protein per sample were fractionated by SDS-PAGE (12\% polyacrylamide) and electroblotted to Immobilon-P membranes (Millipore, Bedford, MA). Transfer efficiency was confirmed by Coomassie blue staining of the gels after electroblotting. The blots were preblocked for $45 \mathrm{~min}$ in $5 \%$ nonfat milk and then incubated overnight at $4^{\circ} \mathrm{C}$ in primary antibody rom 1D5 (1:20 dilution) or rho 1D4 (1:2000 dilution) in PBS and $0.1 \%$ Triton X-100 with $1 \%$ nonfat milk. Primary antibodies were detected using HRP-conjugated donkey antimouse antibody (Jackson Immunoresearch) followed by chemiluminescent detection (DuPont NEN, Boston, MA). Densitometric analyses were performed using NIH Image 1.57 software. Statistical significance was determined by ANOVA.

\section{RESULTS}

\section{Adenovirus-mediated gene transfer}

In homozygous $r d s$ mice, a progressive loss of photoreceptors is seen beginning around postnatal day 7 (P7) that leads to a complete loss of these cells over a period of one year. Because the rate of apoptotic photoreceptor loss is maximal during the third and fourth postnatal weeks (Chang et al., 1993; Portera-Cailliau et al., 1994), we chose to carry out all experimental procedures on P21 homozygous $r d s$ mice. To expose the photoreceptors to sustained levels of CNTF, we have injected the replication- 

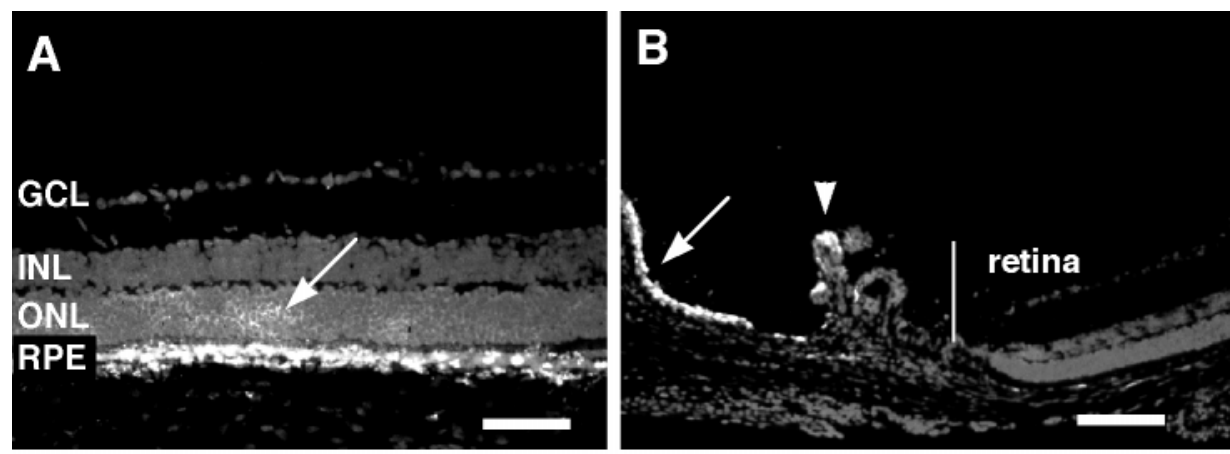

Figure 1. Microphotographs of retinal sections from $r d s / r d s$ eyes injected with adenoviral vectors and processed for anti-CNTF or anti- $\beta$-gal immunofluorescence. $A, B$, Four days after injection of the Ad-CNTF vector, many CNTF-immunopositive $\left(\mathrm{CNTF}^{+}\right)$ cells (white profiles) can be seen in the RPE, ONL $(A$, arrow), and also in the ciliary body and corneal endothelium ( $B$, arrowhead and arrow, respectively). $C$, Fourteen days after Ad-CNTF injection, some eyes still display $\mathrm{CNTF}^{+}$cells in the RPE (arrow). D, CNTFlike immunofluorescence was found below detection level (see Results) in the neural retina, RPE, ciliary body, or iris epithelium of Ad-LacZ-injected eyes at all survival times examined (here, $4 \mathrm{~d}$ p.i.), as well as those of uninjected eyes (data not shown). $E, F$, Two adjacent retinal sections from an eye collected $4 \mathrm{~d}$ after injection of the Ad-LacZ vector, and respectively processed for anti- $\beta$ gal and anti-CNTF immunofluorescence. Although many $\beta$-gal ${ }^{+}$cells are found directly at the needle penetration site and in neighboring RPE cells (E, white profiles), no $\mathrm{CNTF}^{+}$is seen in these same regions $(F)$. Counterstaining: propidium iodide (gray). Scale bars: $A, C, E, F, 50 \mu \mathrm{m} ; B, D, 100 \mu \mathrm{m}$.
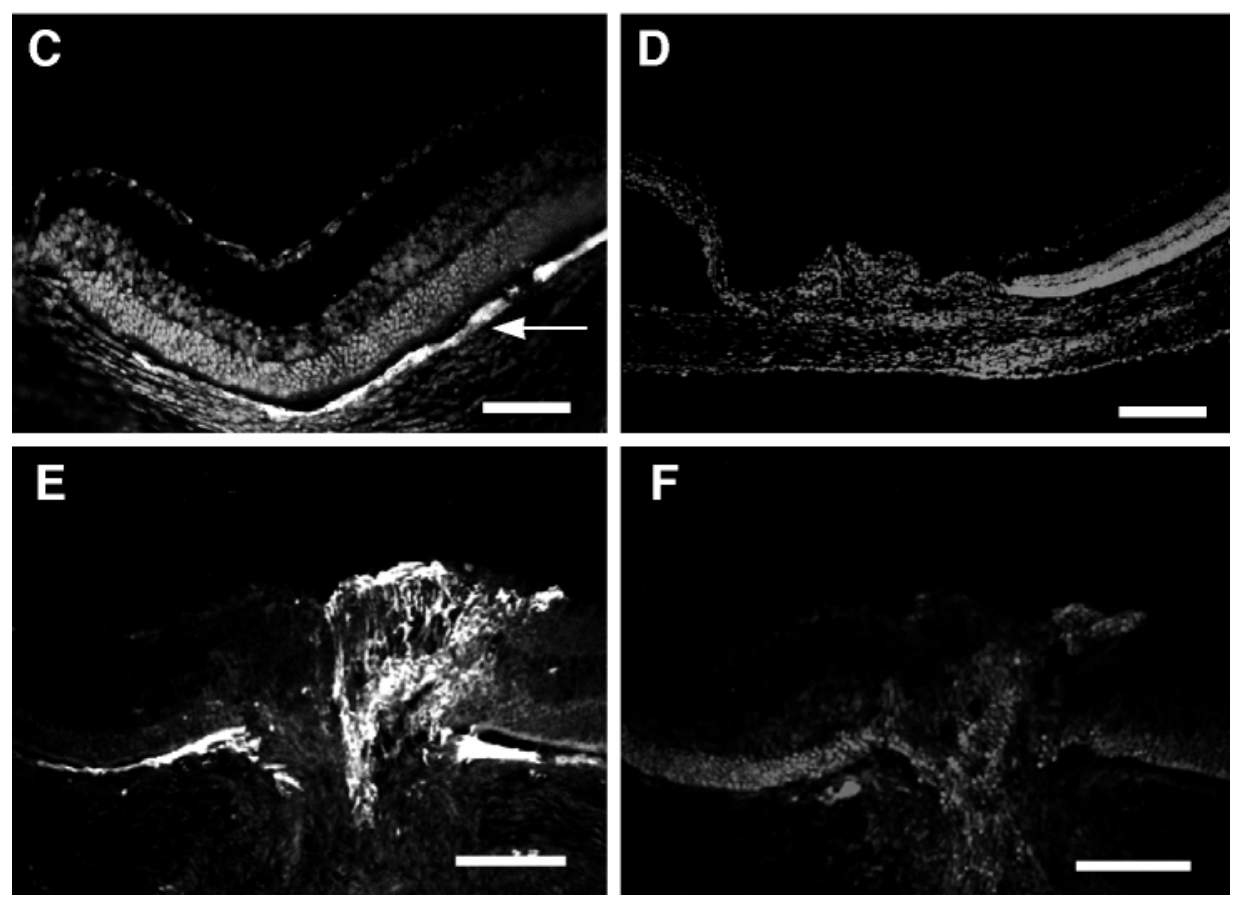

defective adenoviral vector Ad-CNTF (Cayouette and Gravel, 1997) into the vitreous body using a transretinal approach. This vector encodes a cntf gene fused to the leader sequence of the nerve growth factor gene (Sendtner et al., 1992) to allow secretion of the encoded product from vector-transduced cells. This chimeric gene is under the control of the cytomegalovirus immediate/early promoter. In all cases, the Ad-CNTF vector was injected into only one eye for each animal, while the other eye (referred to as the control eye) was either injected with vehicle solution, or with a similar replication-defective adenoviral vector (Ad-LacZ) (Vilquin et al., 1995) encoding E. coli $\beta$-galactosidase under the control of the same cytomegalovirus promoter, or was left uninjected.

At 4 and 14 d p.i., many highly positive CNTF-immunofluorescent cells were detected in all eyes injected with Ad-CNTF. In most eyes, many CNTF-immunopositive cells were seen in the retinal pigment epithelium (RPE), centered around the needle penetration site and extending over several hundred micrometers in all directions (Fig. 1A,C). In some cases, a few CNTFimmunopositive photoreceptors were also observed in the region of the ONL directly overlying the positive RPE cells (Fig. $1 A$ ). In addition to RPE and photoreceptor cells, many cells of the corneal endothelium, of the ciliary body, and of the trabecular meshwork were found to be immunopositive for CNTF in Ad-CNTF-injected eyes (Fig. 1B). In contrast, no specific CNTF- like immunofluorescence was seen in these cell populations in eyes that were noninjected, injected with vehicle only, or injected with the Ad-LacZ vector (Fig. 1D). In particular, no CNTF-like immunofluorescence was seen in cells directly surrounding the needle track, including cells that were found to be immunopositive for $\beta$-galactosidase ( $\beta$-gal) in eyes injected with Ad-LacZ (Fig. 1E,F), confirming that the CNTF-like immunofluorescence detected in eyes injected with Ad-CNTF was not the result of a lesion response or a nonspecific response to infection. In AdLacZ-injected eyes, the distribution and type of vectortransduced $\left(\beta-\mathrm{Gal}^{+}\right)$cells was essentially identical, with most immunopositive cells being found in the RPE around the needle track, the corneal endothelium, the ciliary body, and the trabecular meshwork. This distribution of transgene-expressing cells suggests that the vector was indeed delivered into the vitrous body (Bennett et al., 1994; Li et al., 1994; Li and Davidson, 1995), but that a backflow occurred after withdrawal of the needle, leading to some leakage into the subretinal space and infection of RPE and photoreceptors. A similar distribution of vectorinfected cells was found after transretinal intravitreal injections of the Ad-CNTF and Ad-LacZ vectors in the $r d$ mouse (Cayouette and Gravel, 1997). As expected from E1-deleted adenoviral vectors (Bennett et al., 1994; Li et al., 1994; Li and Davidson, 1995; Cayouette and Gravel, 1997), adenovirus-mediated gene expres- 

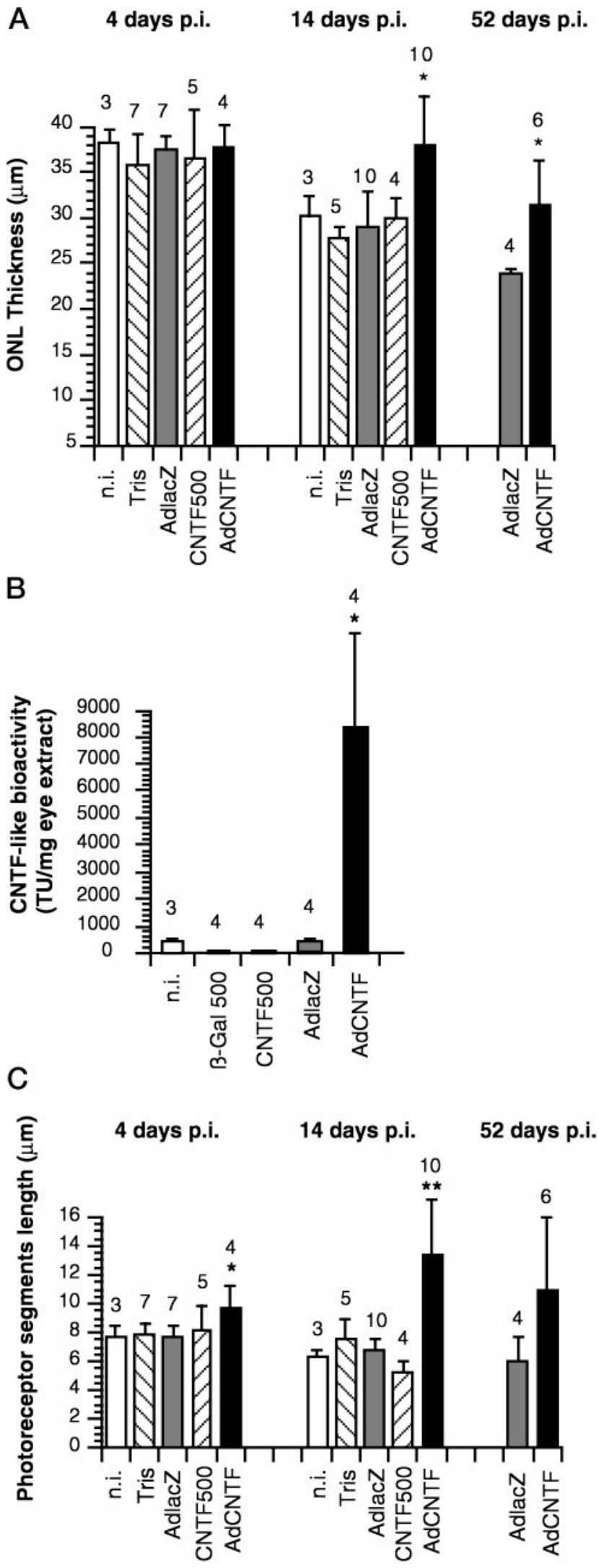

Figure 2. Quantitative analysis of the thickness of the photoreceptor layer, of CNTF-like bioactivity, and of the length of photoreceptor segments in the eyes of $r d s / r d s$ mice after intravitreal injection of various solutions. Numbers above the bars represent the number of eyes processed for each group. $A$, Mean thickness of the $\mathrm{ONL}$ (micrometers $\pm \mathrm{SD}$ ) is not sion was found to be only transient, and no specific CNTF-like immunofluorescence was seen $52 \mathrm{~d}$ after Ad-CNTF injection.

Because CNTF is expressed in the developing and adult retina (Kirsch et al., 1997), we investigated whether our failure to detect CNTF immunoreactivity in eyes not injected with the Ad-CNTF vector could be caused by a lack of sensitivity of the immunofluorescence technique. For this purpose, some sections were processed for CNTF immunohistochemistry using a more sensitive alkaline phosphatase immunodetection technique. Under these conditions, CNTF staining was detected in glial cells of the ganglion cell layer and in presumptive Schwann cells in the ciliary body of uninjected, vehicle-injected, and Ad-LacZ-injected eyes (data not shown) but not in cells of the RPE, the corneal endothelium, or in photoreceptors. These results confirm that, as previously described for the rat retina (Stöckli et al., 1991; Watanabe and Raff, 1992; Kirsch et al., 1997), some cells produce CNTF in the mouse retina. They also reveal that the majority of cells that are transduced by Ad vectors after our injection procedure are different from those that constitutively produce CNTF in the retina.

\section{Effects on photoreceptor survival}

To evaluate the impact of virus-mediated CNTF gene transfer on photoreceptor loss, we estimated the mean thickness of the ONL over the ventral retina (to avoid the needle artifact in the dorsal retina) of $r d s / r d s$ animals at 4,14 , and $52 \mathrm{~d}$ after intravitreal injection of either Ad-CNTF or various control solutions at P21, and used this estimate as an indicator of the number of photoreceptors present in these eyes (Michon et al., 1991). Quantitative results are presented in Figure $2 A$. At P25, no significant difference in ONL thickness was seen between the uninjected eyes and the contralateral eyes injected $4 \mathrm{~d}$ earlier with Ad-CNTF, AdLacZ, vehicle, or $500 \mathrm{ng}$ of rrCNTF, but this result is unsurprising because over such a short period (P21-P25), no significant change in terms of ONL thickness was observed in uninjected $r d s / r d s$ eyes (data not shown). At P35, the mean ONL thickness of uninjected $r d s / r d s$ eyes was found to be significantly smaller than that of eyes at P25, and a similar reduction was seen in the contralateral eyes that were injected with vehicle or with the Ad-LacZ vector, as well as in the eyes injected with $500 \mathrm{ng}$ of rrCNTF, suggesting that the single injection of buffer, irrelevant viral vector, or recombinant CNTF had little or no influence on photoreceptor death over a $14 \mathrm{~d}$ period. In contrast, the mean ONL thickness of P35 eyes injected at P21 with the Ad-CNTF vector was found to be significantly larger than that of uninjected or control-injected eyes (Fig. $3 A-C$ ), suggesting that the presence of the Ad-CNTF vector had caused a reduction in photoreceptor loss over the $14 \mathrm{~d}$ period. Indeed, the mean ONL thickness of the Ad-CNTF-injected eyes collected at P35 is not significantly dif-

significantly different between noninjected eyes (n.i.), Tris-glycerolinjected eyes (Tris), Ad-LacZ-injected eyes (AdlacZ), eyes injected with 500 ng $\operatorname{rrCNTF}$ (CNTF500), and eyes injected with Ad-CNTF (AdCNTF) at $4 \mathrm{~d}$ p.i. However, at $14 \mathrm{~d}$ p.i. and $52 \mathrm{~d}$ p.i., Ad-CNTF-injected eyes display a significantly thicker ONL than those uninjected or injected with other solutions ( ${ }^{*} p<0.02$, ANOVA). $B$, At 4 d p.i., eyes injected with AdCNTF show a significantly higher content in CNTF-like bioactivity than eyes left uninjected or injected with $500 \mathrm{ng}$ of $\beta$-galactosidase ( $\beta$-Gal 500), $500 \mathrm{ng}$ of rrCNTF, or Ad-LacZ $\left({ }^{*} p<0.002\right)$. $C$, Photoreceptor segments are significantly longer in the retina of Ad-CNTF-injected eyes than in the retina of all other groups at 4 and 14 d p.i. $\left({ }^{*} p<0.05 ;{ }^{* *} p<0.0001\right)$. Although a general trend toward longer segments is observed at $52 \mathrm{~d}$ p.i., the difference is not statistically significant $(p>0.05)$. 
Figure 3. Photomicrographs of retinal sections from the eye of a wild-type $(+/+)$ mouse, and from the eyes of P35 rds/rds mice $(-/-r d s)$ injected at P21 into one eye with Ad-LacZ and into the other eye with AdCNTF. $A-C$, Hematoxylin-eosin staining. In a wild-type retina $(A)$, the ONL is made up of 11-12 rows of photoreceptor nuclei, and the photoreceptor segments display two regions: the inner segment $(I S)$ and the outer segment $(O S)$. In the eye of a P35 homozygous $r d s$ mouse that was injected with AdLacZ on P21 (B), the retina displays an ONL reduced to 7 or 8 rows of photoreceptors bearing short segments, and a similar histology is seen in noninjected, P35 rds/rds eyes (data not shown). In contrast, the retina of the contralateral eye of the same animal that was injected at P21 with Ad-CNTF $(C)$ displays an ONL still comprising 9-10 rows of photoreceptors, and these photoreceptors bear longer segments than those of the AdLacZ-injected eye. The insert in $C$ shows a higher magnification of the photoreceptor segments. GCL, Ganglion cell layer; $I N L$, inner nuclear layer. $D-F$, Anti-rhodopsin immunofluorescence. In the wild-type retina $(D)$, rhodopsin-like immunofluorescence (FITC, labeling appears green, and/or yellow where seen superimposed on propidium iodide-positive nuclei that emit in the red) is concentrated almost exclusively in the outer segment of photoreceptors, with the cell body and inner segment displaying very low levels of rhodopsin. In the eye of a P35 rds/rds mouse that received Ad-LacZ on $\mathrm{P} 21(E)$, or in a noninjected P35 $r d s / r d s$ eye (data not shown), rhodopsin-like immunofluorescence is concentrated in the cell body and inner segment of photoreceptors. In the AdCNTF-injected eye of the same animal $(F)$, strong rhodopsin-like immunofluorescence is seen in the distal portion of the photoreceptor segments, whereas the proximal portion of the segment (the boundaries of which are indicated by a double-headed arrow) and the cell body are almost devoid of rhodopsin in most photoreceptors. $G-I$, Rom- 1 immunohistochemistry. In the wild-type retina $(G)$, rom-1-like immunoreactivity (black) is essentially concentrated in the outer segments. In the Ad-LacZ-injected eye of a P35 rds/rds animal $(H)$, the majority of segments shows little or no rom-1-like immunoreactivity, although some short, rom-1-positive, globular profiles (arrows) can be seen decorating a subset of segments. In the contralateral eye injected at P21 with Ad-CNTF (I), a dramatic increase in the density and size of rom-1positive profiles is seen in the distal region of the photoreceptor segments. Scale bars: $A-F$, $25 \mu \mathrm{m} ; G-I, 10 \mu \mathrm{m}$.
$+/+$

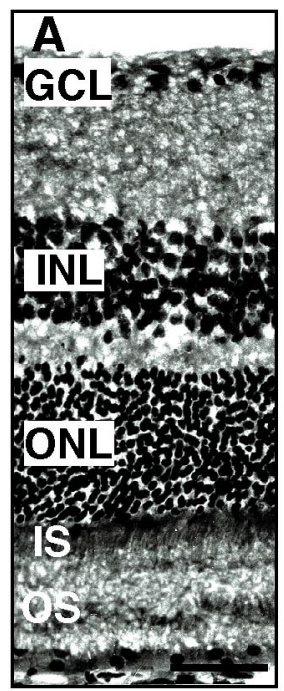

$-/-$ rds
AdLacz
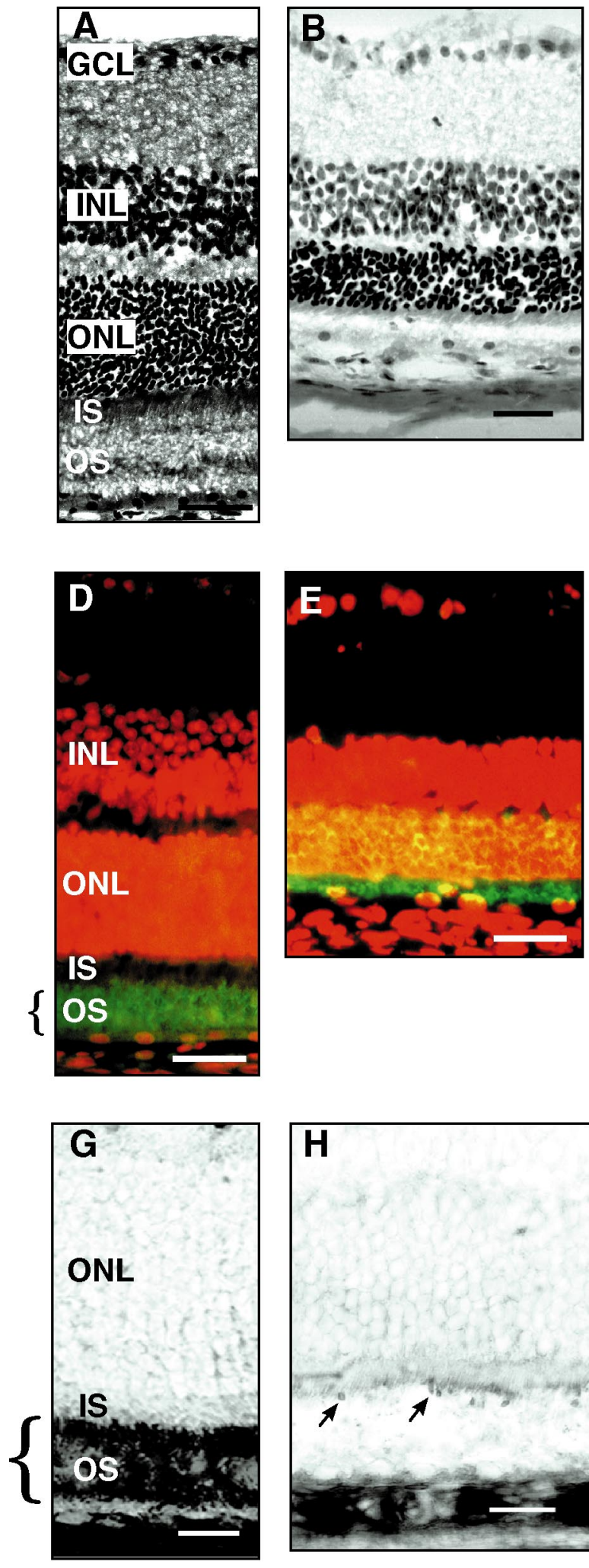

$$
\text { (1) }
$$

ferent from that of P25 eyes, suggesting that little, if any, photoreceptor loss had occurred since the injection of the Ad-CNTF vector. To confirm that the larger ONL thickness of Ad-CNTFinjected eyes was caused by a reduction in photoreceptor loss and
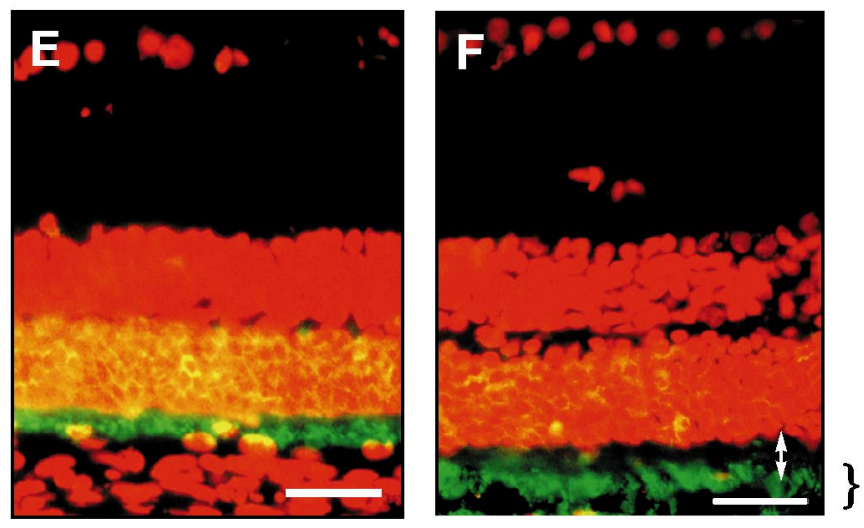
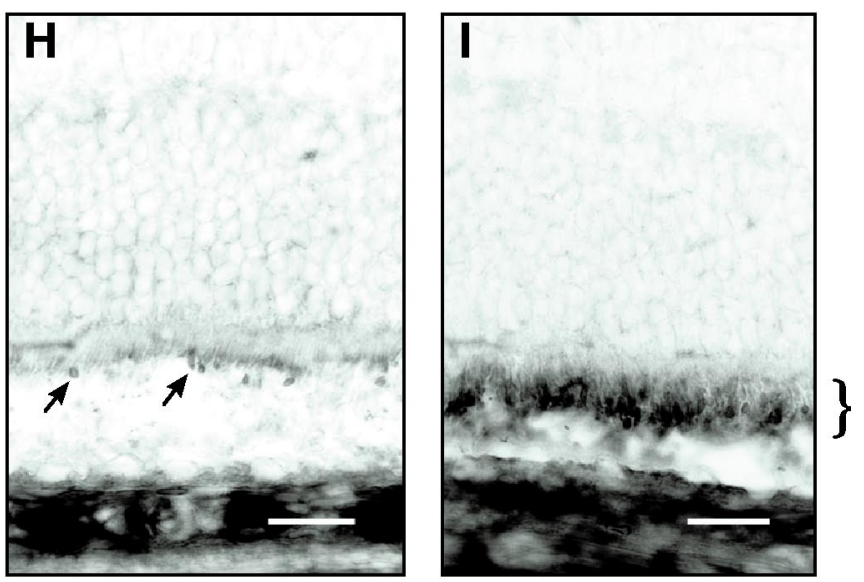

AdCNTF

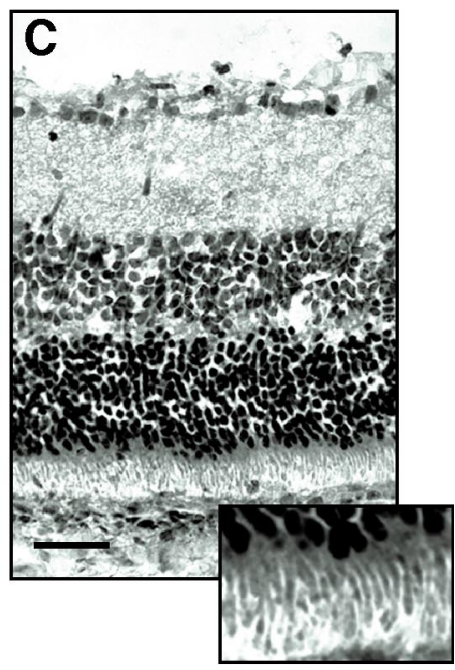

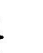

(not by a swelling of the retinal tissues, the mean ONL column not by a swelling of the retinal tissues, the mean ONL column
height (Michon et al., 1991) was estimated from the same sections by counting the number of photoreceptor rows composing the $\mathrm{ONL}$ at regular intervals along the length of the ventral retina. As 
expected, we found that the eyes of $r d s / r d s$ animals that were injected at P21 with Ad-CNTF displayed a significantly larger number of photoreceptor rows at P35 than those left uninjected or injected with Ad-LacZ, with vehicle, or with $\operatorname{rrCNTF}$, and that the number of photoreceptor rows in these Ad-CNTF-treated P35 eyes was not significantly different from that of uninjected P25 rds/rds eyes (data not shown), confirming that little, if any, loss of photoreceptors had occurred in the CNTF-treated eyes over the treatment period. At P73, $52 \mathrm{~d}$ after vector injection, the eyes injected with the Ad-CNTF vector still displayed a significantly thicker ONL composed of more rows of photoreceptors than the controls (Ad-LacZ-injected), and although the results suggest a tendency for a decrease of the mean ONL thickness in comparison with that of P25 eyes, the difference does not reach statistical significance.

The apparent absence of a protective effect resulting from rrCNTF injection in $r d s / r d s$ eyes (Lavail et al., 1998), compared with the protection afforded by injection of the Ad-CNTF vector, could be caused by a difference in the resulting level of bioactive intraocular CNTF protein available to photoreceptors. To test this hypothesis, eye extracts were prepared and subjected to CNTF bioassays (Hughes et al., 1988). Among the extracts collected $4 \mathrm{~d}$ after intravitreal injection of various solutions in the eyes of P21 rds/rds mice (Fig. $2 B$ ), very high levels of CNTF-like bioactivity were found in the extracts from eyes injected with the Ad-CNTF vector. In contrast, the content in CNTF-like bioactivity in the extracts from eyes injected with $\mathrm{rCNTF}$ did not differ from controls. This suggests that rrCNTF rapidly loses its biological activity in oculo, thus becoming no longer available to degenerating photoreceptors.

\section{Effects on the morphology and protein content of photoreceptors}

Photoreceptors in homozygous $r d s$ mouse have no OS, the membranal stacks normally harboring the opsin photopigments (Sanyal et al., 1980; Jansen and Sanyal, 1984; Travis et al., 1992). In rod photoreceptors, the absence of OS results in the accumulation of rhodopsin, which normally accounts for $\sim 80 \%$ of the protein content of rod OS (ROS) (Kuhn et al., 1984) into the cell body and inner segment (Nir and Papermaster, 1986). We found that photoreceptor segments of the Ad-CNTF-injected eye, while still shorter than those of a wild-type animal, were significantly longer than those of the contralateral uninjected or control-injected eye at 4 and $14 \mathrm{~d}$ after vector injection (Fig. 2C). At $52 \mathrm{~d}$ after vector injection, while some of the Ad-CNTF-injected eyes still displayed long photoreceptor segments (data not shown), the difference in mean segment length between Ad-CNTF- and Ad-LacZinjected eyes was no longer statistically significant (Fig. 2C). Because at this survival time, CNTF-like immunofluorescent cells could no longer be found in the retina (see above), this result suggests that a tonic supply of CNTF is required for the sustained growth and/or stabilization of these longer segments.

Rhodopsin immunohistochemistry (Fig. $3 D-F$ ) revealed that the distal region of these segments contains high levels of rhodopsin-like immunofluorescence, while virtually no immunofluorescence could be observed in the proximal region. Moreover, the level of rhodopsin-like immunoreactivity found in the cell body of photoreceptors seems to decrease after CNTF treatment, because only a minority of ONL profiles were found to be rhodopsin-positive $14 \mathrm{~d}$ after Ad-CNTF injection, while virtually all ONL profiles and inner segments were immunopositive in the control contralateral eye. Such a change in the distribution of
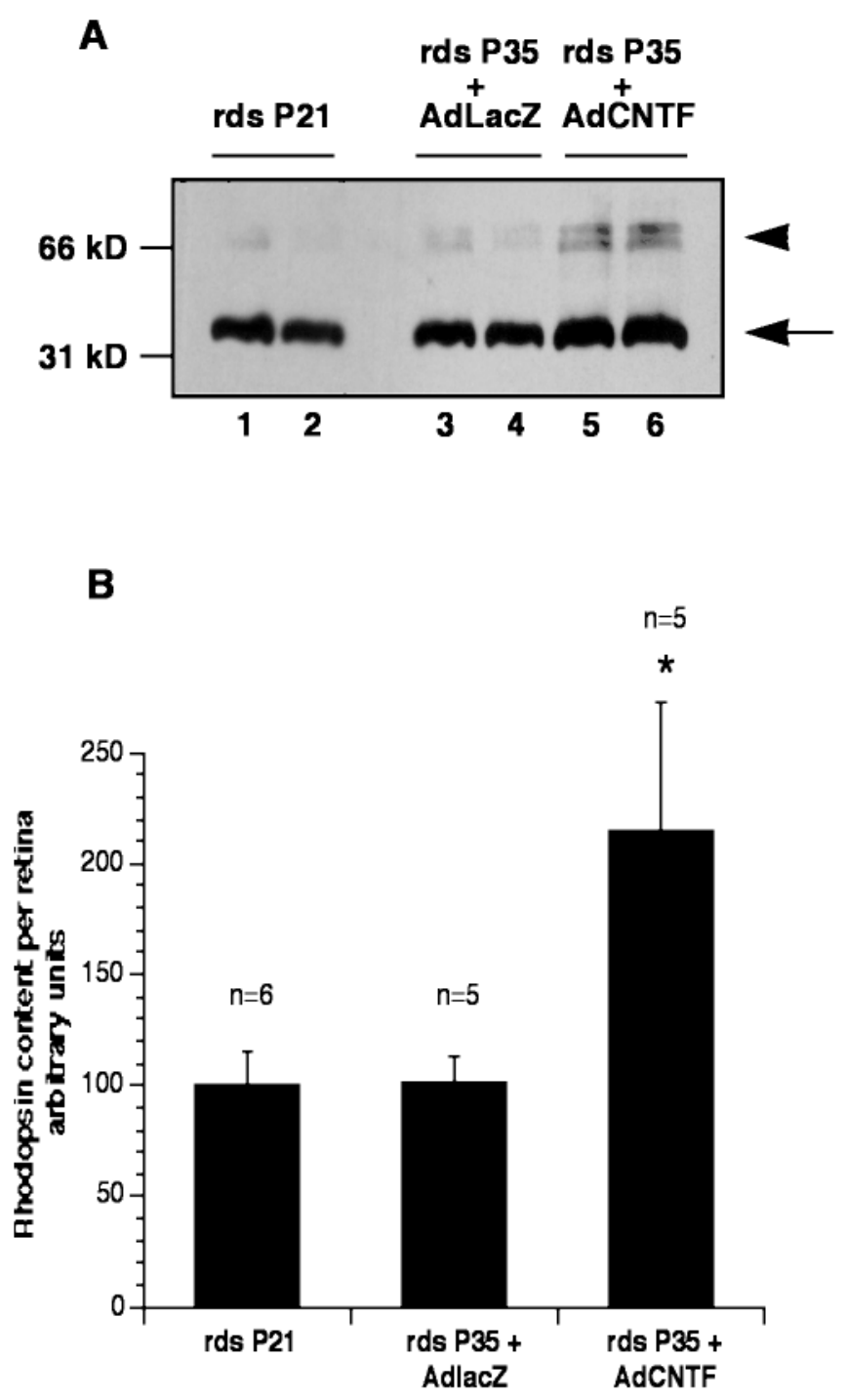

Figure 4. Quantitative analysis of rhodopsin content in $r d s / r d s$ retinas. $A$, Digital image of an immunoblot probed with the anti-rhodopsin rho1D4 antibody. Each lane contains 3 ug of a protein extract from one retina that has been separated by SDS-PAGE. Lanes 1 and 2, Samples from untreated P21 rds/rds eyes; lanes 3 and 4, samples from P35 rds/rds eyes injected at P21 with Ad-LacZ; lanes 5 and 6, samples from P35 rds/rds eyes injected at P21 with Ad-CNTF. The main opsin band (arrow) is seen at an apparent mobility of $\sim 35 \mathrm{kDa}$ with fainter bands, corresponding to oligomeric forms (Molday and MacKenzie, 1983), showing lower mobility (arrowhead). B, Densitometric analysis was performed on the main opsin band using immunoblots similar to that shown in $A$, and the readings were corrected for the total protein content of each retina and expressed as arbitrary units of rhodopsin. Duplicate samples were run and analyzed in multiple immunoblots to correct for interblot variations. The content of $\mathrm{P} 21 \mathrm{rds} / \mathrm{rds}$ retinas was attributed a value of 100 . Retinas from P35 rds/rds eyes injected with Ad-CNTF at P21 contain approximately two times more rhodopsin (ANOVA, $p<0.0002$ ). The number $(n)$ of retinas analyzed for each group is shown above each bar.

rhodopsin immunoreactivity could be caused by either a decrease in the rhodopsin content of photoreceptors in CNTF-treated eyes or by a redistribution and preferential accumulation of rhodopsin to the distal portion of segments. To investigate this question, we have compared the total content in rhodopsin between experimental and control $r d s / r d s$ eyes using eye extracts (Fig. 4). In P35 $r d s / r d s$ eyes injected at P21 with the Ad-LacZ vector, the total amount of rhodopsin per retina was found to be essentially 
identical to that of $\mathrm{P} 21 \mathrm{rds} / \mathrm{rds}$ eyes. In contrast, the total amount of rhodopsin per retina present in $\mathrm{P} 35 \mathrm{rds} / \mathrm{rds}$ eyes injected at $\mathrm{P} 21$ with Ad-CNTF was found to be about twice that measured in P21 $r d s / r d s$ retinas or in $\mathrm{P} 35 r d s / r d s$ retinas injected at $\mathrm{P} 21$ with AdLacZ. This suggests that the decrease in rhodopsin-like immunoreactivity observed in the cell body and proximal segment of the rod photoreceptors in Ad-CNTF-injected eyes results from the translocation and accumulation of rhodopsin into the distal end of the segment, a phenomenon reminiscent of the translocation occurring during normal retinal development (Nir et al., 1984; Nir and Papermaster, 1986).

To verify whether the distal region of the photoreceptor segments in the Ad-CNTF-injected eyes could be made of outer segment-like membranes, immunohistochemistry was performed using a monoclonal antibody recognizing the rom-1 protein, a structural component of the ROS disks normally associated with the rds/peripherin protein (Bascom et al., 1992; Goldberg et al., 1995; Moritz and Molday, 1996) (Fig. 3G-I). In the retina of wild-type mice, strong rom-1 like immunoreactivity was seen concentrated in the OS of photoreceptors, with only very weak staining of the inner segments and photoreceptor cell bodies. In the untreated or control-treated eye of our P35 rds/rds mice, the majority of photoreceptor segments display little if any rom-1-like immunoreactivity, although some segments, harboring rom-1positive globular profiles at their tip (Fig. $3 H$ ), can be seen unevenly distributed in these tissues. These rom-1 containing globular profiles may correspond to the vesicular expansions protuding from the distal cilia that have been reported in previous studies (Jansen and Sanyal, 1984; Nir and Papermaster, 1986) and that are thought to represent abortive outer segments (Nir and Papermaster, 1986). In contrast, strong rom-1 immunoreactivity is seen concentrated throughout the distal portion of the photoreceptor segments in the retina of $\mathrm{P} 35 \mathrm{rds} / \mathrm{rds}$ eyes that have been injected with Ad-CNTF on P21 in a pattern similar to that seen for rhodopsin immunofluorescence. Densitometric analysis of Western blots probed with the anti-rom-1 antibody revealed no significant difference in the concentration of the rom-1 protein between retinal extracts from P35 rds/rds eyes injected at P21 with Ad-LacZ or with Ad-CNTF (data not shown), suggesting that CNTF overexposure leads to increased translocation and/or accumulation of rom-1 into the distal portion of the segments, but has no net effect on the total protein content in rom-1. Taken together, the accumulation of both rhodopsin and rom-1 in the distal region of photoreceptor segments in the Ad-CNTF-treated eyes suggests that cell membranes in this portion of the segment share some biochemical characteristics with ROS membranes.

\section{Effects on photoreceptor function}

In light of the results described above, we have evaluated the impact of CNTF gene transfer and expression on the retinal function of the $r d s / r d s$ mouse. For this purpose, in vivo ERG recordings were performed on $\mathrm{P} 21$ uninjected mutants, and on P35 mutants having received an injection of the Ad-CNTF vector into one eye at P21, while the contralateral eye was either left uninjected or was injected with the Ad-LacZ vector. For comparison, ERG recordings were also obtained from adult wild-type mice. Recordings and data analysis were performed by an experimenter blinded to the treatment applied to each eye. Representative tracings of scotopic (rod-mediated) responses are shown in Figure 5, and group data analysis is presented in Figure 6.

At P21, before treatment, $r d s / r d s$ mice yielded rod-mediated ERGs with severely impaired responses. In these animals, the average a- and b-wave amplitudes reached only $8.2 \pm 2.6 \mu \mathrm{V}$ and $22.8 \pm 4 \mu \mathrm{V}$, respectively, at the brightest stimulus intensity, representing only $\sim 10$ and $7 \%$, respectively, of the average a- and b-wave amplitudes recorded from wild-type mice. Fourteen days later (P35), equivalent ERG responses were obtained from both noninjected and Ad-LacZ-injected eyes of $r d s / r d s$ animals. Data analysis revealed no statistically significant change in average a-wave and b-wave amplitudes between those recorded at P21 and those recorded at P35 from either uninjected or Ad-LacZinjected eyes.

In sharp contrast, scotopic ERG responses with prominent aand b-wave components were recorded from the contralateral eye of these P35 rds/rds mice that was injected with the Ad-CNTF vector on P21. The average amplitudes recorded from these eyes at the highest stimulus intensity (a-wave, $19.3 \pm 5.1 \mu \mathrm{V}$; b-wave, $43.7 \pm 4.0 \mu \mathrm{V}$ ) were about twice those recorded from the uninjected or Ad-LacZ injected eyes or from the eyes of P21 rds/rds animals, representing a statistically significant increase (a-wave, $p<0.04$; b-wave, $p<0.005$, one-way ANOVA). Intensityresponse analysis revealed that the average amplitudes of both waves generated in the CNTF-treated eye of P35 rds/rds mice were significantly larger than those recorded in the contralateral eye at all but the weakest stimulus intensities (data not shown).

ERG recordings were also obtained from the same animals under photopic (cone-mediated) conditions. As expected from studies carried on heterozygous ( $r d s /+)$ mice (Cheng et al., 1997), the photopic ERG of $r d s / r d s$ mice is also severely affected by the absence of rds/peripherin, and the amplitude of the responses is significantly smaller than that seen in a normal mouse (Fig. $7 A-C$ ). However, in contrast to the results obtained for rodmediated responses in the same eyes (Fig. $7 D-F$ ), we found no evidence that the cone-mediated photopic ERG recorded at P35 had benefited from the Ad-CNTF injection performed on P21, and data analysis revealed no significant difference in photopic amplitudes recorded at maximal stimulus intensity between untreated, Ad-LacZ-injected, and Ad-CNTF-injected eyes at P35 (data not shown).

At the end of the recording sessions, the animals were killed, and the eyes were collected for histological and immunohistochemical analyses. As seen in the previously analyzed tissues, the retinas of the $\mathrm{P} 35 \mathrm{rds} / \mathrm{rds}$ mice that were exposed to the AdCNTF vector from P21 display more rows of photoreceptors, longer photoreceptor segments, and an extensive redistribution of rhodopsin toward the distal portion of the segments when compared with the contralateral uninjected or Ad-LacZ-injected retina (Fig. $5 C, D$ ).

\section{DISCUSSION}

Our results clearly demonstrate that in the homozygous $r d s$ mouse, a tonic increase in the intraocular concentration of CNTF results in a significant increase in photoreceptor survival and a net increase in the amplitude of rod-mediated responses to light. These effects are accompanied by significant changes in the morphology of photoreceptor segments, the intracellular distribution of photoreceptor-specific proteins, and an increase in the total retinal content of rhodopsin, the photopigment responsible for the light sensitivity of rods. Because the rhodopsin content and the amplitude of the scotopic ERG measured in Ad-CNTFinjected eyes were found to be significantly increased in comparison to those found before injection of the vector, our results show that in addition to preventing cell death, exposure to supranormal 


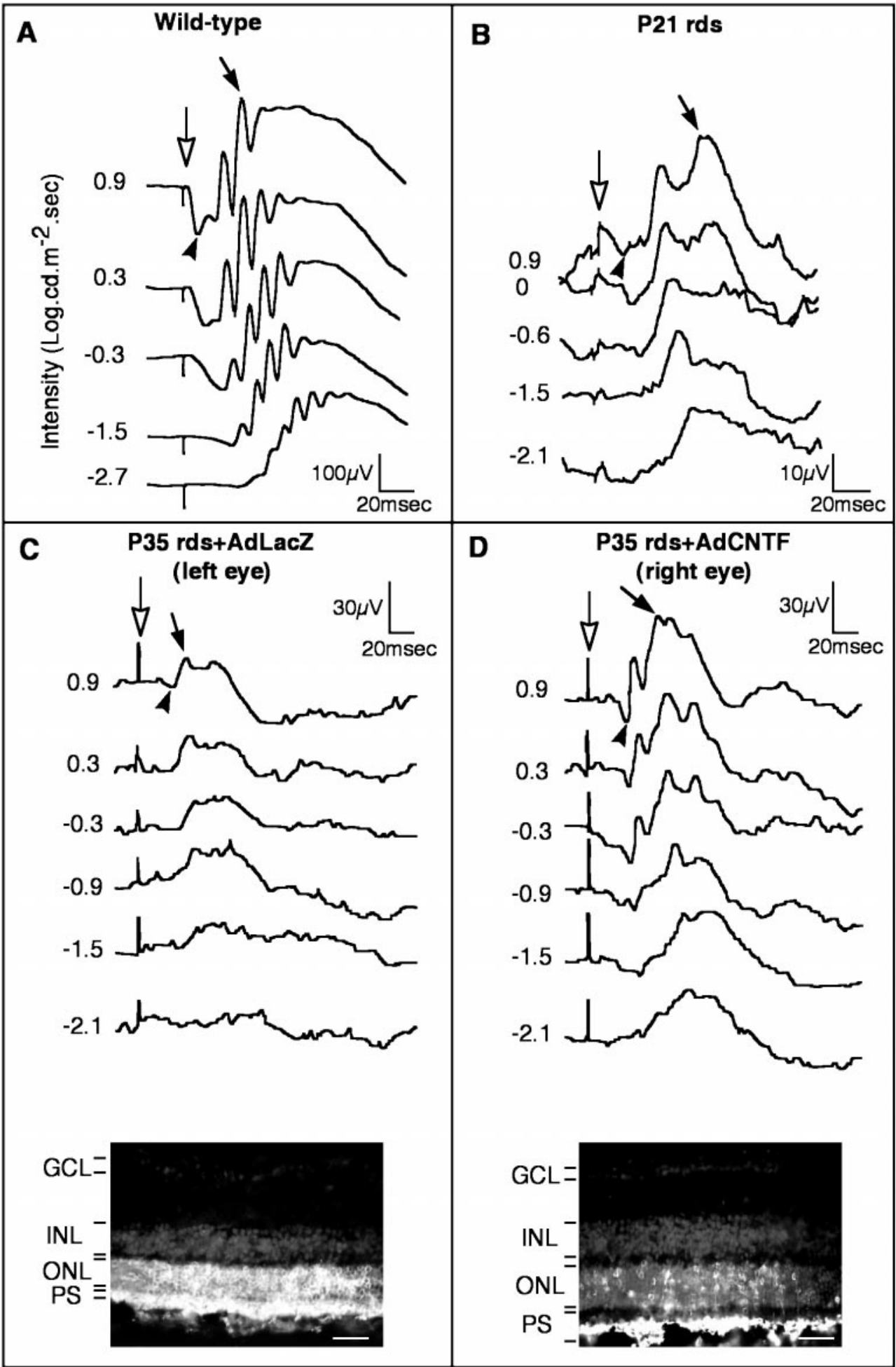

Figure 5. Representative electroretinographic intensity-response functions obtained from an eye of a wild-type mouse $(A)$, an eye from a $\mathrm{P} 21 \mathrm{rds} / \mathrm{rds}$ mouse $(B)$, and from the left eye $(C)$ and right eye $(D)$ of a $\mathrm{P} 35 \mathrm{rds} / \mathrm{rds}$ mouse having received an intravitreal injection of Ad-CNTF (AdCNTF) into the right eye at P21 (the left eye received AdLacZ). The electroretinograms were recorded in dark-adapted conditions using flashes of white light, the intensity of which is indicated in $\log \mathrm{cd} / \mathrm{m}^{-2} / \mathrm{sec}$ at the left of each trace. The white vertical arrows point to flash onset. Note that the vertical calibration bar is $100 \mu \mathrm{V}$ in $A$, $10 \mu \mathrm{V}$ in $B$, and $30 \mu \mathrm{V}$ in $C$ and $D$. The amplitude of both the a-wave (arrowhead) and b-wave (arrow) are much reduced in the eyes of $r d s / r d s$ animals compared with that of a wild-type mouse. However, the eye of a P35 rds/rds mouse having received an intravitreal injection of Ad-CNTF $14 \mathrm{~d}$ before recording $(D)$ displays a- and b-wave amplitudes that are noticeably larger than those recorded in the contralateral, AdLacZ-injected eye $(C)$, or than those recorded in a noninjected $r d s / r d s$ eye at P21 (B). The inserts $(C, D$, bottom $)$ are digitalized photomicrographs from retinal sections collected from the recorded eyes, and processed for anti-rhodopsin immunofluorescence (anti-rho; white). Note the thicker ONL, the longer PSs, and the redistribution of rhodopsin to the distal portion of the segments in the Ad-CNTF-injected eye $(D)$. GCL, ganglion cell layer; $I N L$, inner nuclear layer. Counterstaining: propidium iodide (gray). Scale bar of photomicrographs, $35 \mu \mathrm{m}$. levels of CNTF can also allow, or trigger, a significant increase in the functionality of surviving rods over their original condition. These effects are specific for CNTF because, in the same animals, they were not seen in the contralateral eye that was left uninjected, was injected with vehicle, or was injected with a similar vector encoding the $l a c Z$ gene. While in the rat, a lesion of the retina can cause a local rescue of neighboring photoreceptors (Faktorovich et al., 1990, 1992); such a phenomenon is reportedly absent in the murine retina (Yasumura et al., 1995; LaVail et al.,
1998) and indeed, we saw no such rescue in our various control eyes. Moreover, the CNTF effects in the $r d s / r d s$ retina apparently depend on a tonic supply of the protein because we, and others (LaVail et al., 1998), were unable to observe them after a single intravitreal injection of CNTF protein in amounts sufficient to reduce photoreceptor death in other models of photoreceptor loss in rats and mice (LaVail et al., 1992, 1998; Cayouette and Gravel, 1997). The rapid decrease in CNTF content after injection of the purified protein, combined with the slow rate of 


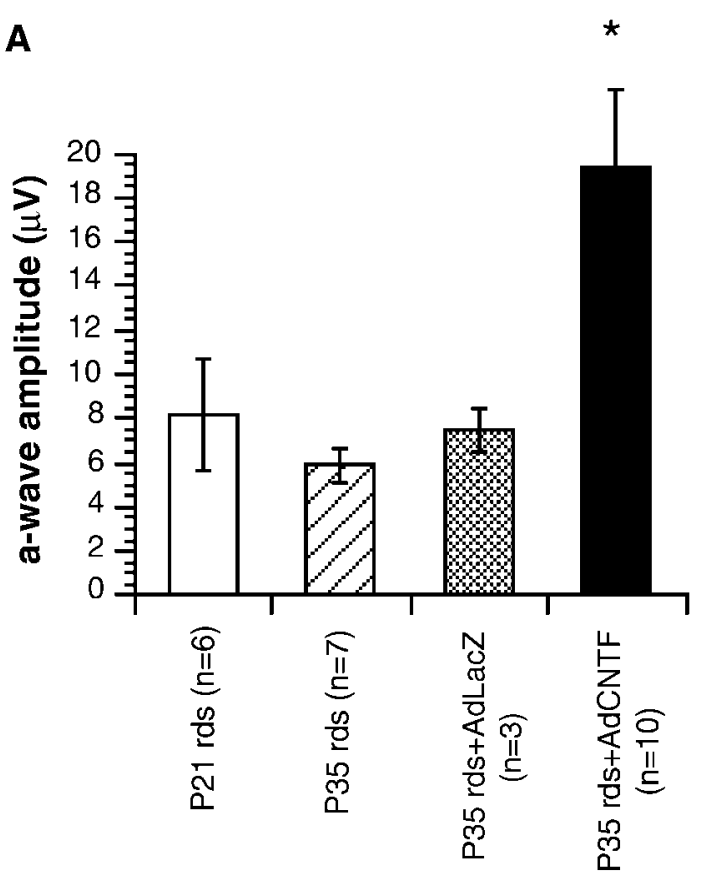

B

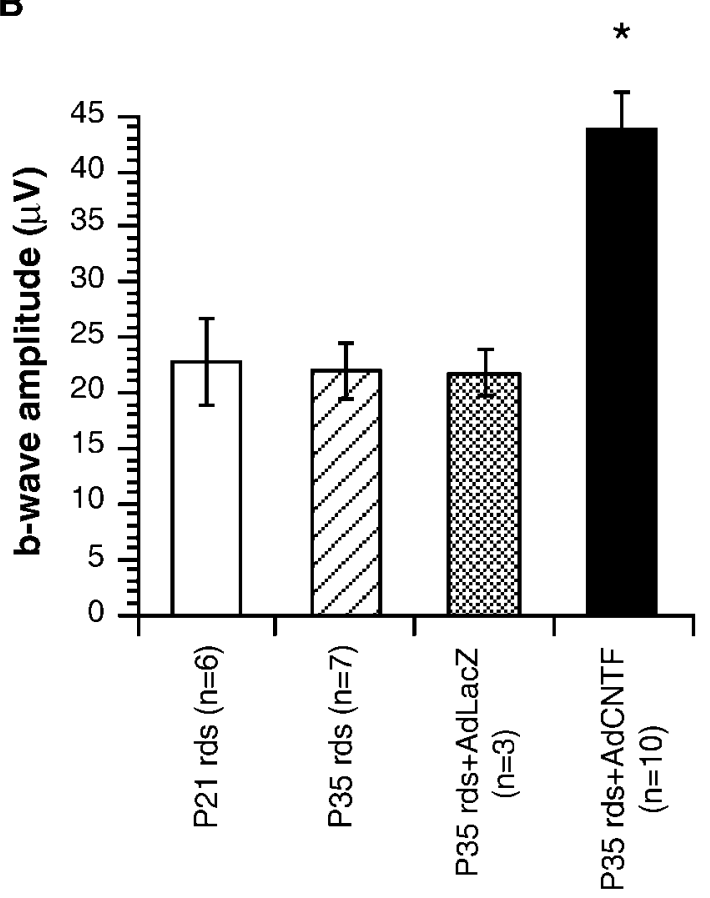

Figure 6. Quantitative analysis of the mean maximal amplitude of scotopic a-wave $(A)$ and b-wave $(B)$ in homozygous $r d s$ mice. The maximal amplitudes were calculated (see Material and Methods) from recordings obtained from the eyes of three $r d s / r d s$ mice at P21 (both eyes recorded) and from the eyes of $10 \mathrm{rds} / \mathrm{rds}$ mice at P35 that received Ad-CNTF at P21 into one eye (P35 rds $+A d C N T F ; n=10)$, and either Ad-LacZ (P35 rds + AdLacZ; $n=7)$ or nothing (P35 rds; $n=3)$ into the contralateral eye. Stimulus intensity was $0.9 \mathrm{log} \mathrm{cd} / \mathrm{m}^{-2} / \mathrm{sec}$ in all cases. In $A$, the results show that essentially similar maximal a-wave amplitudes are obtained at P21 and P35 from uninjected eyes and that injection of the Ad-LacZ vector $14 \mathrm{~d}$ before recording had no apparent impact on this parameter. In contrast, the maximal amplitude recorded at P35 in the eyes injected with Ad-CNTF at P21 is more than twice that recorded from the contralateral uninjected or Ad-LacZ-injected eye, or that recorded from P21 eyes $\left({ }^{*} p<0.04\right.$, ANOVA). Data analysis comparing both eyes of a same animal confirms that a significantly larger maximal a-wave amplitude is reached in the Ad-CNTF-injected eye for both CNTF versus
Photopic

Scotopic

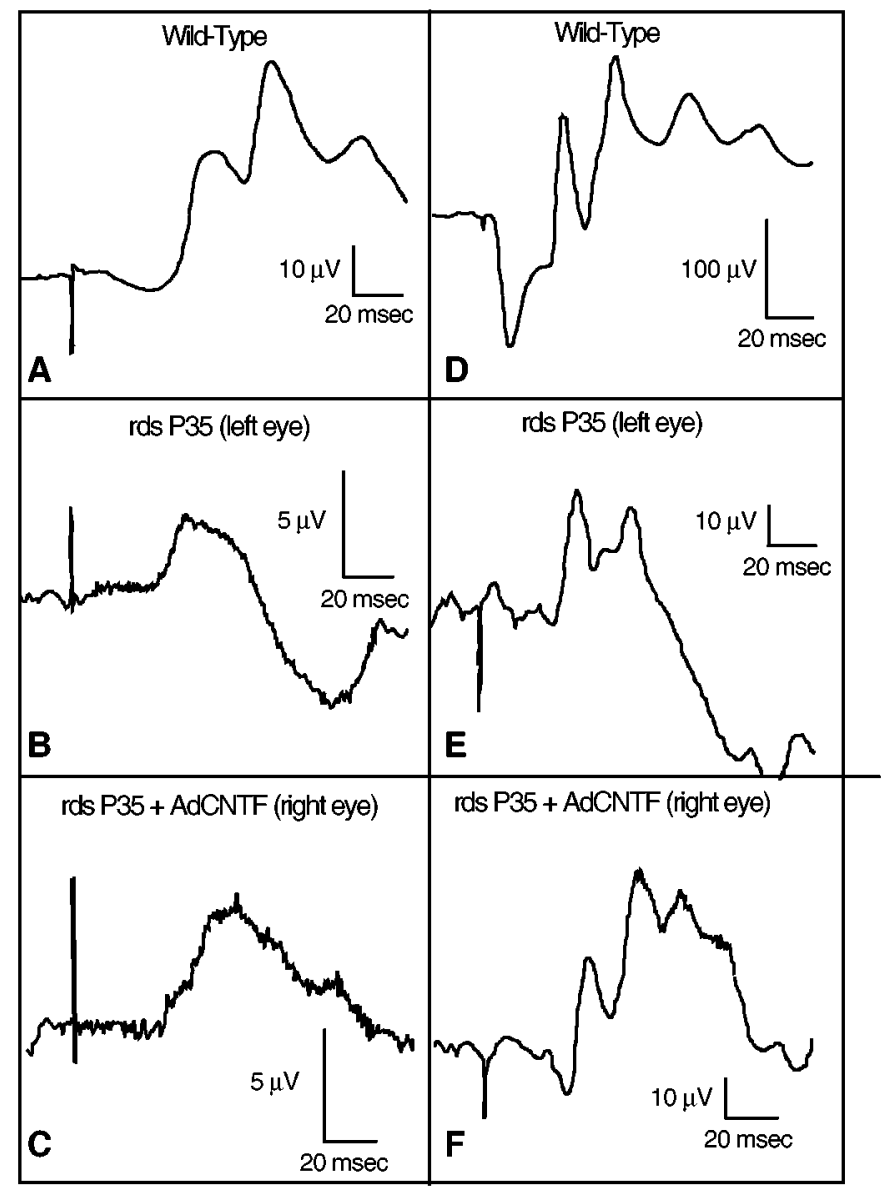

Figure 7. Representative photopic and scotopic ERG recordings from the eye of a wild-type mouse and from both eyes of a P35 rds/rds mouse having received an injection of Ad-CNTF into the right eye at P21 (the left eye received no injection). The amplitude of both the photopic and scotopic responses in the uninjected eye of the mutant mouse is severely reduced in comparison to that recorded in the eye of the wild-type animal. However, although a marked improvement is observed in the scotopic response of the Ad-CNTF-injected eye when compared with that of the contralateral eye, only a slight modification is seen in the photopic response. Flash intensity was set at $0.9 \mathrm{log} \mathrm{cd} / \mathrm{m}^{-2} / \mathrm{sec}$ for both photopic and scotopic recordings.

photoreceptor death in this particular mutant, probably explains this result.

$\mathrm{Rds} /$ peripherin is an integral membrane glycoprotein involved in the stabilization of the rims of the outer segment disks of photoreceptors through homophilic and heterophilic interactions with closely related proteins like rom-1 (Goldberg et al., 1995; Goldberg and Molday, 1996). In homozygous $r d s$ animals, the absence of rds/peripherin results in the failure to elaborate photoreceptor outer segments, and vesicular material containing rho-

$\leftarrow$

uninjected $(n=7)$, and CNTF versus LacZ groups $(n=3)$ (paired $t$ tests, $p<0.04$ and $p<0.03$, respectively). In $B$, a comparison of the mean maximal b-wave amplitude yielded essentially the same results as in $A$, with P35 eyes injected at P21 with Ad-CNTF showing a significantly larger b-wave amplitude than the contralateral eyes left uninjected or injected with Ad-LacZ, or than the b-wave amplitude recorded at P21 (ANOVA, * $p<0.005$ ). 
dopsin is seen budding from the inner segment of rods into the subretinal space (Nir and Papermaster, 1986). We have shown here that in these animals, the rod (rhodopsin-positive) photoreceptor segments grow significantly longer in the eye treated with CNTF, that the distal half of these segments displays strong rom-1 immunoreactivity, and that rhodopsin preferentially segregates and accumulates in this region, suggesting that the distal portion of these segments is composed of ROS-like membranes. However, because rds/peripherin appears essential for the elaboration of the membranal disks composing normal ROS (Travis et al., 1992; Kedzierski et al., 1997) and the segments of the CNTFtreated $r d s / r d s$ retina are still shorter and more disorganized than that of a wild-type retina, it appears unlikely that the CNTF treatment could have corrected the defect in the stabilization of ROS disks associated with this rds/peripherin null mutant. Because CNTF displays neurite-promoting activity on some neuronal populations (Bianchi and Cohan, 1993; Carri et al., 1994; Oyesiku and Wigston, 1996; Syed et al., 1996; Guo et al., 1997), a more parsimonious hypothesis would be that, by stimulating synthesis of membranous material, the CNTF treatment could have shifted the balance between the rate of generation of abortive ROS membranes and the rate of their shedding, leading to accumulation of these ROS membranes. The increase in density and size of rom-1-positive structures decorating photoreceptor segments that is seen after CNTF treatment could, thus, be the result of an accelerated enlargement of the short, rom-1-positive, vesicular expansions normally found on a subset of photoreceptor segments in the $r d s / r d s$ retina (Jansen and Sanyal, 1984; Nir and Papermaster, 1986; see also Fig. $3 H$ ). Confirmation of such an hypothesis will await evaluation of protein turnover rates in the photoreceptor segments of CNTF-treated eyes and ultrastructural analysis.

Whatever the mechanism mediating the increase in the length of rod segments, such a phenomenon likely participates to the net increase in scotopic ERG responses occurring between P21 and P35 in Ad-CNTF-injected eyes. Rhodopsin being a transmembrane protein, an increase in segment length should translate into an increased capacity to accommodate rhodopsin. Because the scotopic a-wave amplitude is function of the rhodopsin content of rods (Fulton and Baker, 1984; Fulton et al., 1995), such a phenomenon should result in an increased responsiveness of rods, provided that rhodopsin biosynthesis is not limiting. Our results show that in the untreated $r d s / r d s$ retina, there is a decrease of $\sim 22 \%$ in ONL thickness between P21 and P35, corresponding to a loss of about three rows of photoreceptors, yet the scotopic a-wave amplitude as well as the total retinal content in rhodopsin remain unchanged during that period. This suggests that an increase in the rhodopsin content per rod is occurring between P21 and P35 in the retina of the $r d s / r d s$ mouse, as in the wild-type retina during normal development (Carter-Dawson et al., 1986). Although both the rhodopsin content and scotopic ERG of $r d s / r d s$ mice gradually declines over the following months (Reuter and Sanyal, 1984; Schalken et al., 1990), surviving rods remain strongly immunopositive for rhodopsin (Nir and Papermaster, 1986; Cantera et al., 1990), and cell loss is likely the main cause of this decline. These observations suggest that the maximal content in rhodopsin of the $r d s / r d s$ retina is dictated both by the the limited capacity of rods to increase their membrane surface area and by the total number of rods. In a situation in which cell loss is prevented and the growth and/or stability of segment membranes is increased, as is seen in eyes injected with the Ad-CNTF vector, a net increase in the total retinal content in rhodopsin and, in turn, in the amplitude of the scotopic ERG is observed.

The rds/peripherin gene is expressed in both cone and rod photoreceptors, and both cell types are morphologically and functionally affected by the null mutation (Sanyal et al., 1980; Jansen and Sanyal, 1984; Reuter and Sanyal, 1984; Cheng et al., 1997). However, we have been unable to document an effect of the CNTF treatment on the photopic ERG, suggesting that cones respond differently, or not at all, to CNTF. This hypothesis is strengthened by the finding that in the $r d$ mouse, intravitreal injection of purified CNTF can prevent the death of rods, but not that of cones (LaVail et al., 1998). At the present time, the question as to whether cones express the CNTF receptor complex and can respond in some way to CNTF, is unanswered.

Whether the increased photoreceptor survival and photoreceptor segment length seen after intraocular CNTF gene transfer result from a direct action of $\mathrm{CNTF}$ on the photoreceptors themselves is not known. CNTF is present in the developing and adult retina (Kirsch et al., 1997), and postmitotic rod retinal progenitors respond to CNTF in vitro and express the mRNA encoding the CNTF-receptor $\alpha$ (CNTFR- $\alpha$ ) (Fuhrmann et al., 1995; Kirsch et al., 1996, 1997; Ezzeddine et al., 1997). Although no survival-promoting activity is seen, and no neurite-promoting activity is reported on opsin-positive cells after CNTF exposure in vitro (Fuhrmann et al., 1995; Ezzeddine et al., 1997; Kirsch et al., 1997; Neophytou et al., 1997), the facts that photoreceptors do not survive for prolonged periods in culture and never grow a significant outer segment in vitro preclude the study of CNTF actions on mature, fully differentiated photoreceptors in culture. Photoreceptors do differentiate and survive for at least $11 \mathrm{~d}$ in retinal explant cultures from newborn CNTFR- $\alpha$ knock-out mice (Ezzeddine et al., 1997), showing that the CNTF signaling pathway is not strictly required for early differentiation events and short-term survival of photoreceptors. Nonetheless, by analogy with observations made on motoneurons of CNTF and CNTFR- $\alpha$ knock-out mice (Masu et al., 1993; DeChiara et al., 1995), it may be that CNTF and/or another as yet unidentified ligand for CNTFR- $\alpha$ is required for long-term survival and proper function of fully differentiated photoreceptors, in particular under pathophysiological conditions such as in $r d s / r d s$ mice. Alternatively, because other retinal cell types like ganglion cells (Mey and Thanos, 1993) and RPE cells (Gupta et al., 1997) do respond to CNTF, the possibility remains that CNTF could act indirectly via other cell types in vivo or could require the synergistic action of another factor. Such possibilities should now be investigated because the elucidation of the pathway mediating CNTF actions on photoreceptors could have important clinical consequences for the treatment of several forms of photoreceptor diseases.

\section{REFERENCES}

Bascom RA, Manara S, Collins L, Molday RS, Kalnins VI, McInnes RR (1992) Cloning of the cDNA for a novel photoreceptor membrane protein (rom-1) identifies a disk rim protein implicated in human retinopathies. Neuron 8:1171-1184.

Bedell MA, Largaespada DA, Jenkins NA, Copeland NG (1997) Mouse models of human disease. Part II: Recent progress and future directions. Genes Dev 11:11-43.

Bennett J, Wilson J, Sun D, Forbes B, Maguire A (1994) Adenovirus vector-mediated in vivo gene transfer into adult murine retina. Invest Ophthalmol Vis Sci 35:2535-2542.

Bennett J, Tanabe T, Sun D, Zeng Y, Kjeldbye H, Gouras P, Maguire AM (1996) Photoreceptor cell rescue in retinal degeneration (rd) mice by in vivo gene therapy. Nature Med 2:649-654. 
Bianchi LM, Cohan CS (1993) Effects of the neurotrophins and CNTF on developing statoacoustic neurons: comparison with an otocystderived factor. Dev Biol 159:353-365.

Cantera R, von Schantz M, Chader GJ, Ehinger B, Sanyal S, van Veen T (1990) Postnatal development of photoreceptor-specific proteins in mice with hereditary retinal degeneration: an immunocytochemical study. Exp Biol 48:305-312.

Carri NG, Richardson P, Ebendal T (1994) Choroid coat extract and ciliary neurotrophic factor strongly promote neurite outgrowth in the embryonic chick retina. Int J Dev Neurosci 12:567-578.

Carter-Dawson L, Alvarez RA, Fong SL, Liou GI, Sperling HG, Bridges CD (1986) Rhodopsin, 11-cis vitamin A, and interstitial retinolbinding protein (IRBP) during retinal development in normal and $\mathrm{rd}$ mutant mice. Dev Biol 116:431-438.

Cayouette M, Gravel C (1997) Adenovirus-mediated gene transfer of ciliary neurotrophic factor can prevent photoreceptor degeneration in the retinal degeneration (rd) mouse. Hum Gene Ther 8:423-430.

Chang G-Q, Hao Y, Wong F (1993) Apoptosis: final common pathway of photoreceptor death in $r d, r d s$, and rhodopsin mutant mice. Neuron 11:595-605.

Cheng T, Peachey NS, Li S, Goto Y, Cao Y, Naash MI (1997) The effect of peripherin/rds haploinsufficiency on rod and cone photoreceptors. J Neurosci 17:8118-8128.

DeChiara TM, Vajsada R, Poueymirou WT, Acheson A, Suri C, Conover JC, Friedman B, McClain J, Pan L, Stahl N, Ip NY, Kato A, Yancopoulos GD (1995) Mice lacking the CNTF receptor, unlike mice lacking CNTF, exhibit profound motor neuron deficits at birth. Cell 83:313-322.

Dryja TP, Li T (1995) Molecular genetics of retinitis pigmentosa. Hum Mol Genet 4:1739-1743.

Ezzeddine ZD, Yang X, DeChiara T, Yancopoulos G, Cepko CL (1997) Postmitotic cells fated to become rod photoreceptors can be respecified by CNTF treatment of the retina. Development 124:1055-1067.

Faktorovich EG, Steinberg RH, Yasamura D, Matthes MT, LaVail MM (1990) Photoreceptor degeneration in inherited retinal dystrophy delayed by basic fibroblast growth factor. Nature 347:83-86.

Faktorovich EG, Steinberg RH, Yasumura D, Matthes MT, LaVail MM (1992) Basic fibroblast growth factor and local injury protect photoreceptors from light damage in the rat. J Neurosci 12:3554-3567.

Fuhrmann S, Kirsch M, Hofmann H-D (1995) Ciliary neurotrophic factor promotes chick photoreceptor development in vitro. Development 121:2695-2706.

Fulton AB, Baker BN (1984) The relation of retinal sensitivity and rhodopsin in developing rat retina. Invest Ophthalmol Vis Sci 25:647-651.

Fulton AB, Hansen RM, Findl O (1995) The development of the rod photoresponse from dark-adapted rats. Invest Ophthalmol Vis Sci 36:1038-1045.

Goldberg AFX, Molday RS (1996) Defective subunit assembly underlies a digenic form of retinitis pigmentosa linked to mutations in peripherin/rds and rom-1. Proc Natl Acad Sci USA 93:13726-13730.

Goldberg AFX, Moritz OL, Molday RS (1995) Heterologous expression of photoreceptor peripherin/rds and rom- 1 in COS-1 cells: assembly, interactions, and localization of multisubunit complexes. Biochemistry 34:14213-14219.

Guo X, Metzler-Northrup J, Lein P, Rueger D, Higgins D (1997) Leukemia inhibitory factor and ciliary neurotrophic factor regulate dendritic growth in cultures of rat sympathetic neurons. Dev Brain Res 104:101-110.

Gupta S, Jollimore CA, McLaren MJ, Inana G, Kelly ME (1997) Mammalian retinal pigment epithelial cells in vitro respond to the neurokines ciliary neurotrophic factor and leukemia inhibitory factor. Biochem Cell Biol 75:119-125.

Hughes S, Lillen M, Raff LE, Rohrer C, Sendtner M (1988) Ciliary neurotrophic factor induces type-2 astrocyte differentiation in culture. Nature 335:70-73.

Ip NY, Yancopoulos GD (1996) The neurotrophins and CNTF: two families of collaborative neurotrophic factors. Annu Rev Neurosci 19:491-515.

Jansen HG, Sanyal S (1984) Development and degeneration of retina in $r d s$ mutant mice: electron microscopy. J Comp Neurol 224:71-84.

Jomary C, Vincent KA, Grist J, Neal MJ, Jones SE (1997) Rescue of photoreceptor function by AAV-mediated gene transfer in a mouse model of inherited retinal degeneration. Gene Ther 4:683-690.
Kedzierski W, Lloyd M, Birch DG, Bok D, Travis GH (1997) Generation and analysis of transgenic mice expressing P216L-substituted rds/ peripherin in rod photoreceptors. Invest Ophthalmol Vis Sci 38:498-509.

Kirsch M, Fuhrmann S, Wiese A, Hofmann H-D (1996) CNTF exerts opposite effects on in vitro development of rat and chick photoreceptors. NeuroReport 7:697-700.

Kirsch M, Lee MY, Meyer V, Wiese A, Hofmann H-D (1997) Evidence for multiple, local functions of ciliary neurotrophic factor (CNTF) in retinal development: expression of CNTF and its receptor and in vitro effects on target cells. J Neurochem 68:979-990.

Kuhn H, Hall SW, Wilden U (1984) Light-induced binding of 48-kDa protein to photoreceptor membranes is highly enhanced by phosphorylation of rhodopsin. FEBS Lett 176:473-478.

Lachapelle P, Blain L (1990) A new speculum electrode for electroretinography. J Neurosci Methods 32:245-249.

Lachapelle P, Benoit J, Blain L, Guite P, Roy MS (1990) The oscillatory potentials in response to stimuli of photopic intensities delivered in dark-adaptation: an explanation for the conditioning flash effect. Vision Res 30:503-513.

Lambiase A, Aloe L (1996) Nerve growth factor delays retinal degeneration in C3H mice. Graefe's Arch Clin Exp Ophthalmol 234:S96-S100.

LaVail MM, Unoki K, Yasumura D, Matthes MT, Yancopoulos GD, Steinberg RH (1992) Multiple growth factors, cytokines, and neurotrophins rescue photoreceptors from the damaging effects of constant light. Proc Natl Acad Sci USA 89:11249-11253.

LaVail MM, Yasumura D, Matthes MT, Lau-Villacorta C, Unoki K, Sung CH, Steinberg RH (1998) Protection of mouse photoreceptors by survival factors in retinal degenerations. Invest Ophthalmol Vis Sci 39: 592-602.

Li T, Davidson BL (1995) Phenotype correction in retinal pigment epithelium in murine mucopolysaccharidosis VII by adenovirus-mediated gene transfer. Proc Natl Acad Sci USA 92:7700-7704.

Li T, Adamian M, Roof DJ, Berson EL, Dryja TP, Roessler BJ, Davidson BL (1994) In vivo transfer of a reporter gene to the retina mediated by an adenoviral vector. Invest Ophthalmol Vis Sci 35:2543-2549.

Masu Y, Wolf E, Holtmann B, Sendtner M, Brem G, Thoenen H (1993) Disruption of the CNTF gene results in motor neuron degeneration. Nature 365:27-32.

Mey J, Thanos S (1993) Intravitreal injections of neurotrophic factors support the survival of axotomized retinal ganglion cells in adult rats in vivo. Brain Res 602:304-317.

Michon JJ, Li Z-L, Shioura N, Anderson RJ, Tso MOM (1991) A comparative study of methods of photoreceptor morphometry. Invest Ophthalmol Vis Sci 32:280-284.

Molday RS, MacKenzie D (1983) Monoclonal antibodies to rhodopsin: characterization, cross-reactivity, and application as structural probes. Biochemistry 22:653-660.

Molday RS, Hicks D, Molday L (1987) Peripherin. A rim-specific membrane protein of rod outer segment discs. Invest Ophthalmol Vis Sci 28:50-61.

Moritz OL, Molday RS (1996) Molecular cloning, membrane topology, and localization of bovine Rom-1 in rod and cone photoreceptor cells. Invest Ophthalmol Vis Sci 37:352-362.

Neophytou C, Vernallis AB, Smith A, Raff MC (1997) Muller-cellderived leukaemia inhibitory factor arrests rod photoreceptor differentiation at a postmitotic pre-rod stage of development. Development 124:2345-2354.

Nir I, Papermaster DS (1986) Immunocytochemical localization of opsin in the inner segment and ciliary plasma membrane of photoreceptors in retinas of $r d s$ mutant mice. Invest Ophthalmol Vis Sci 27:836-840.

Nir I, Cohen D, Papermaster DS (1984) Immunocytochemical localization of opsin in the cell membrane of developing rat retinal photoreceptors. J Cell Biol 98:1788-1795.

Oyesiku NM, Wigston DJ (1996) Ciliary neurotrophic factor stimulates neurite outgrowth from spinal cord neurons. J Comp Neurol 364:68-77.

Peachey NS, Alexander KR, Fishman GA (1987) Rod and cone system contributions to oscillatory potentials: an explanation for the conditioning flash effect. Vision Res 27:859-866.

Portera-Cailliau C, Sung C-H, Nathans J, Adler R (1994) Apoptotic photoreceptor cell death in mouse models of retinitis pigmentosa. Proc Natl Acad Sci USA 91:974-978. 
Reuter JH, Sanyal S (1984) Development and degeneration of retina in $r d s$ mutant mice: the electroretinogram. Neurosci Lett 48:231-237.

Sanyal S, Ruiter AD, Hawkins RK (1980) Development and degeneration of retina in $r d s$ mutant mice: light microscopy. J Comp Neurol 194:193-207.

Schalken JJ, Jansen JJ, Sanyal S, Hawkins RK, de Grip WJ (1990) Development and degeneration of retina in rds mutant mice: immunoassay of the rod visual pigment rhodopsin. Biochim Biophys Acta 1033:103-109.

Sendtner M, Schmalbruch H, Stöckli KA, Carroll P, Kreutzberg GW, Thoenen H (1992) Ciliary neurotrophic factor prevents degeneration of motor neurons in mouse mutant progressive motor neuronopathy. Nature 358:502-504.

Stöckli KA, Lillien LE, Näher-Noé M, Breitfeld G, Hughes RA, Raff MC, Thoenen H, Sendtner M (1991) Regional distribution, developmental changes, and cellular localization of CNTF-mRNA and protein in the rat brain. $\mathrm{J}$ Cell Biol 115:447-459.
Syed N, Richardson P, Bulloch A (1996) Ciliary neurotrophic factor, unlike nerve growth factor, supports neurite outgrowth but not synapse formation by adult Lymnaea neurons. J Neurobiol 29:293-303.

Travis GH, Groshan KR, Lloyd M, Bok D (1992) Complete rescue of photoreceptor dysplasia and degeneration in transgenic retinal degeneration slow (rds) mice. Neuron 9:113-119.

Vilquin J-T, Guérette B, Kinoshita I, Roy B, Goulet M, Gravel C, Roy R, Tremblay JP (1995) FK506 immunosuppression to control the immune reactions triggered by first-generation adenovirus-mediated gene transfer. Hum Gene Ther 6:1391-1401.

Watanabe T, Raff MC (1992) Diffusible rod-promoting signals in the developing rat retina. Development 114:899-906.

Yasumura D, Matthes MT, Lau C, Unoki K, Steinberg RH, LaVail MM (1995) Attempts to rescue photoreceptors with survival factors in mice with inherited retinal degenerations or constant light damage. Invest Ophthalmol Vis Sci 36:S252. 